\author{
Arief Bahtiar Rifai \\ SMP Islam Al Azhar 26 Yogyakarta \\ ariefbahta@gmail.com
}

\section{Permainan Kartu Sebagai Media \\ Pembelajaran untuk Meningkatkan Daya Serap Belajar Siswa (Nahwu)}

DOI: $10.18196 / \mathrm{mht} .2112$

\title{
ABSTRACT
}

This research is an experimental research with a quantitative-qualitative approach with the research population was the eighth grade students of Muhammadiyah Boarding School (MBS) Junior High School, Pleret, Bantul, Yogyakarta in the 2015/2016 Academic Year. This research combined learning and media to increase the absorption of learning or memory in understanding the material. The results of this study indicated that the initial average score of students at 49.67 in pre-test increased to an average of 63.25 in post-test result after getting with the treatment of learning using card media. Getting treated with card media showed an improvement in understanding Arabic language material, especially Nahwu for the eighth grade students of Muhammadiyah Boarding School Junior High School (MBS) Pleret so that the improvement in students' comprehension can be seen in the achievement of the better score.

Keywords: learning media, Nahwu, experiments, card media

\section{ABSTRAK}

Penelitian ini adalah penelitian ekperimen dengan pendekatan kuantitatif-kualitatif dengan populasi kelas VIII jenjang SMP di Muhammadiyah Boarding School (MBS) Pleret Bantul Yogyakarta Tahun Ajaran 2015/2016. Penelitian ini menggabungkan antara pembelajaran dan media untuk meningkatkan daya serap belajar atau daya ingat dalam memahami materi. Hasil dari penelitian ini menunjukkan bahwa nilai rata-rata awal siswa 49,67 pada saat pretest meningkat menjadi rata-rata 63,25 pada saat posttest setelah mendapatkan treatment dengan pembelajaran menggunakan media kartu. Mendapatkan perlakuan dengan media kartu menunjukan adanya peningkatan dalam memahami materi bahasa arab khususnya Ilmu Nahwu di kelas VIII jenjang SMP di Muhammadiyah Boarding School (MBS) Pleret sehingga peningkatan daya serap belajar siswa dapat dilihat dengan prestasi nilai yang dicapai.

Kata kunci: media pembelajaran, Nahwu, eksperimen, media kartu

\section{PENDAHULUAN}

Bahasa adalah salah satu pusat perhatian untuk menganalisa tujuan dan makna pembicara kepada lawan bicara. Secara umum, bahasa dapat diartikan sebagai alat komunikasi yang disepakati bersama dan dipraktikkan di setiap komunitas dan masyarakat luas (Daud, tanpa tahun: 43). Dengan mempelajari bahasa, terutama bahasa asing, kita dapat mengetahui bahwa suatu bahasa memiliki kriteria yang berbeda dengan bahasa lainnya seperti dalam hal penguasaan kosakata, tata bahasa, susunan kalimat, dan fungsi setiap kata yang dipelajari. Di antara bahasa asing yang banyak dipelajari orang adalah bahasa Arab. Di indonesia, bahasa Arab sudah muncul sejak dahulu dan sudah banyak yang menggunakannya sebagai bahasa kedua. Akan 
tetapi, pada kenyataannya, bahasa Arab tidak begitu banyak digunakan di kalangan masyarakat luas. Bahasa Arab hanya digunakan di pesantren-pesantren yang mendalami ilmu agama yang selalu berkaitan erat dengan bahasa Arab saja.

Pembiasaan dalam komunikasi bahasa arab akan terus berlangsung selama kegiatan di lingkungan pesantren. Meskipun demikian, para siswa juga terkadang mencuri-curi kesempatan dengan bahasa Indonesia atau bahkan bahasa-bahasa daerah masing-masing. Hal itu terjadi karena adanya keterbatasan para siswa dalam penguasaan kosakata, kaidah, dan struktur bahasa Arab.

Berdasarkan pengamatan yang telah dilakukan selama penelitian, ada hal yang mendasar dalam keterbatasan siswa dalam memahami tata bahasa Arab, khususnya dalam ilmu Nahwu dan Sharaf. Dengan memahami kedua ilmu ini, siswa akan mudah untuk mempelajari dan membiasakan bahasa Arab dalam keseharian. Tanpa memahami kedua ilmu itu, siswa akan merasakan kesulitan pada saat melafalkan katakata bahasa Arab yang berubah dari bentuk fi'il mâdhi menjadi fi'il mudhâri' dan fi'il amr. Kebiasaan ini sering ditemukan pada saat siswa menceritakan tentang aktivitasnya kepada siswa lain atau ketika membicarakan banyak hal yang berkaitan dengan waktu.

Pada kasus di atas, peneliti melakukan pencatatan kata yang berubah serta maksud pembicara pada kata tersebut sebagai bahan penelitian. Ada beberapa kekeliruan siswa dalam mempraktikkan perubahan kata, terutama yang berkaitan dengan ilmu Sharaf pada bab fi'il mâdhi, fi'il mudhâri', dan fíl amr. Siswa menggunakannya tidak sesuai dengan aturan yang berlaku. Dalam bidang ilmu Nahwu peneliti juga menganalisa kemahiran siswa apakah dalam menuliskan kalimat-kalimat atau ketika berbicara bahasa Arab sesuai dengan ilmu Nahwu atau tidak. Kasus kekeliruan siswa dalam penggunaan ilmu Nahwu ditemui pada saat siswa menulis dan menerjemahkan bahasa Indonesia ke dalam bahasa Arab. Siswa yang telah memahami ilmu Nahwu dan Sharaf biasanya tidak akan kesulitan dalam menerjemahkan struktur kalimat bahasa Arab ke struktur bahasa Indonesia.

Peneliti juga melakukan wawancara dengan guru pengampu bahasa Arab di sekolah tersebut yaitu pada saat pembelajaran telah selesai diberikan kepada siswa sehingga informasi dapat disimak dengan baik secara langsung. Inti dari beberapa pernyataan yang diberikan dan dibenarkan langsung oleh guru adalah bahwa pendalaman ilmu Nahwu dan Sharaf harus lebih ditekankan lagi dengan menambah jumlah jam pelajaran.

Permasalahan-permasalahan yang muncul dapat dirumuskan dengan pembelajaran menggunakan media. Salah satunya adalah media kartu untuk meningkatkan daya serap belajar siswa. Selain itu, juga untuk melihat kenaikan dan perbaikan nilai yang didapat siswa setelah dilakukannya treatment dengan media kartu serta mengetahui kelebihan dan kelemahan dari penggunakan media kartu tersebut.

Kata media atau wasilah dari bahasa Latin yang berarti medius, yang merupakan medium, yang memiliki arti di tengah (Anitah, 2012: 5). Pembelajaran adalah sesuatu yang baru yang akan mencari pengetahuan baik dengan diri sendiri 
atau memerlukan bantuan orang lain yang akan membantu dirinya dalam mengubah perilaku (Asrori 2012, 12). Media pembelajaran merupakan jembatan yang mengantarkan ilmu pengetahuan kepada peserta didik. Di antara media pembelajaran bahasa Arab adalah permainan kartu.

Permainan kartu akan memudahkan peserta didik dalam memahami materi pembelajaran yang telah ditulis oleh guru yang memiliki peran pada media kartu yang akan dimainkan oleh siswa (Khalilullah, 2008: 100). Berbagai macam permainan akan memudahkan peserta didik dalam mendalami bahasa Arab, termasuk permainan kartu yang peneliti terapkan pada siswa MBS Pleret, meskipun pengajar juga memiliki peranan penting dalam mengatur alur pembelajaran yang efektif (Mujib 2012, 81-86).

\section{METODE PENELITIAN}

Metode yang digunakan dalam penelitian ini adalah kuantitatif dan kualitatif. Kedua metode ini digunakan untuk mendapatkan data dan kesesuaian untuk mendukung penelitian.

Penelitian kuantitatif adalah penelitian yang mendukung data menggunakan angka untuk mengukur berapa persen pencapaian siswa dalam menyelesaikan materi atau peningkatan nilai yang berubah pada saat dilakukan pretest (Sugiyono 2013, 13).

Melakukan pretest merupakan hal yang sangat penting dalam pengolahan data awal sehingga memiliki rancangan kelas yang akan dijadikan sebagai kelas eksperimen dalam pembelajaran menggunakan media kartu. Kemudian peneliti mengelompokkan siswa ke dalam kategori kelas kontrol dan kelas eksperimen.

Populasi adalah jumlah keseluruhan yang akan diteliti, sedangkan sampel adalah bagian terkecil dari populasi untuk memudahkan pengambilan data pada penelitian sehingga diperlukan sampel yang akan mendukung dan menjawab penelitian yang sedang berlangsung (Arikunto 2013, 173).

Peneliti juga menggunakan metode kualitatif yang tidak menunjukkan angka dalam penelitian, tetapi membantu dalam penyempurnaan daya dukung kualitatif yang sudah dilakukan (Sugiyono 2013, 13). Dengan menggunakan metode kualitatif, peneliti dapat terjun dan menyaksikan secara langsung proses pembelajaran, baik sebelum penelitian, saat penelitian, atau setelah penelitian karena penelitian ini sifatnya natural. Untuk praktik pembelajaran dengan menggunakan media kartu, maka membutuhkan kelas eksperimen dan kelas non-eksperimen. Kedua kelas ini mendapatkan perlakuan khusus untuk menguji ketepatan dan kegunaan kartu sebagai media pembelajaran dan meningkatkan daya serap belajar siswa.

Desain penelitian yang digunakan peneliti adalah quasi experimental design yaitu salah satu desain penelitian eksperimen yang memiliki kelas atau kelompok yang tetap tetapi tidak mengubah fungsi variabel yang mempengaruhi implementasi percobaan (Sugiyono 2013, 118). Desain ini merupakan desain yang menjadikan pretest dan postest sebagai langkah awal untuk mengetahui kemampuan siswa dalam berbahasa Arab, dengan demikian peneliti menggunakan rumusan (Sugiyono 2013, 116). 


$$
\frac{01 \times 02}{03 \quad 04}
$$

Penjelasan rumus di atas sebagai berikut:

O1 : Nilai awal kelompok percobaan

O2 : Nilai akhir kelompok percobaan

$\mathrm{X} \quad$ : praktik di kelas percobaan

O3 : Nilai awal kelas kontrol

O4 : Nilai akhir kelas kontrol

Rumusan di atas dapat dituliskan $\left(\mathrm{O}_{1}-\mathrm{O}_{2}\right)\left(\mathrm{O}_{3}-\mathrm{O}_{4}\right)$

Lokasi penelitian ini bertempat di Muhammadiyah Boarding School (MBS) Pleret Bantul Daerah Istimewa Yogyakarta. Peneliti memilih lokasi ini karena merupakan sekolah baru sehingga diharapkan dapat terwujud pembelajaran bahasa Arab yang efektif dan tepat sasaran di dalamnya.

\section{Pengumpulan Data penelitian}

Pendukung penelitian lainnya adalah melakukan wawancara, pretest dan posttest, penyebaran angket untuk mengumpulkan data dengan menuliskan pertanyaan-pertanyaan untuk mendukung penelitian (Margono, 2004: 167), observasi, analisis, dan dokumentasi untuk mengumpulkan dan menganalisis dokumen yang ditulis, difotokopi, atau secara elektronik (Sukmadinata 2012, 220).

Wawancara dilakukan setelah observasi yaitu dengan menemui beberapa siswa dan guru pengampu pelajaran sebagai sample pengambilan data, serta melakukan beberapa proses penyelidikan ringan. Observasi dapat dilakukan kapan pun dan di mana pun, serta tidak memiliki batasan waktu (Sugiyono 2013, 203).

Setelah melakukan observasi dan wawancara dengan melakukan tanya jawab dengan beberapa peserta didik dan beberapa guru terkait menggali informasi yang akurat dengan mekalukan wawancara (Sudijono 2013, 82), selanjutnya peneliti mengadakan pretest pada kelas kontrol dan kelas eksperimen untuk melihat hasil yang tertinggi dan terendah sebagai barometer pemetaan siswa yang akan membantu proses penelitian. Pengumpulan data selanjutnya adalah menyebarkan angket kepada siswa sebelum penelitian dan setelah penelitian untuk merencanakan kegiatan serta hal penting lainnya seperti penentuan waktu, media pembelajaran, pertemuan, dan bahan ajar yang akan diberlakukan. Setelah melakukan semua rangkaian penelitian, maka ada satu hal yang terpenting yaitu analisis data. Pada saat analisis data, peneliti membutuhkan energi lebih karena harus melalui proses yang panjang serta memadukan semua data. Pada tahap ini juga, data akan diolah untuk menunjukkan hasil penelitian yang telah dilakukan agar penelitian dapat diketahui hasilnya atau perubahan yang terjadi setelah dilakukannya penelitian.

\section{Analisis Data penelitian}

Analisis kualitatif digunakan dalam penelitian ini sebagai pendukung untuk menjelaskan kenyataan faktual yang ada dari hasil penelitian. Data yang ada akan 
dibuat dengan analisis data kualitatif dan kuantitatif. Untuk analisis data kuantitatif, ada evaluasi siswa dari hasil tes. Analisis kualitatif akan dilakukan melalui analisis deskriptif yang ada dari metode pengumpulan data seperti observasi, dokumentasi, dan kuesioner tentang upgrade penulisan kalimat yang berguna. Peneliti menggunakan formula Likert dalam bentuk memberikan pertanyaan dan jawaban. Masing-masing alat memiliki metode dan jumlah yang bervariasi untuk setiap hari.

Rumusan setelah melakukan penyebaran angket sebagai berikut:

$$
R=\frac{S}{S M} \times 100
$$

Penjelasan:

R : Rata-Rata Respon/ Jawaban Siswa

S : Jumlah Skor Yang Dicapai

SM : Skor Maksimal

\section{Cara Analisis Data}

Analisis data adalah langkah-langkah penting untuk mendapatkan pencarian dan validasi yang bermakna (Satori dan Komarudin 2013, 199). Peneliti menggunakan program SPSS dalam penelitian.

Pertama, menggunakan validasi adalah mengetahui tingkat kompetensi alat untuk melihat data yang sesuai dengan pertanyaan yang akan diberikan. Adapun formula yang digunakan untuk analisis validasi, peneliti mencari bantuan dengan guru. Jenis kebenaran yang peneliti ambil adalah kebenaran isi, termasuk juga memvisualisasikan pengukuran yang terkait dengan pertanyaan evaluasi untuk mengetahui apa yang diukur oleh peneliti (Sukardi 2012, 32).

Kedua, reabilitas adalah alat untuk menunjukkan reabilitas dalam pengukuran dan memiliki kemampuan untuk mendapatkan pengukuran konstan dan tidak berubah dalam penggunaan berturut-turut (Sunarti dan Rahmawati 2014, 98)

Penelitian untuk meningkatkan daya serap belajar ilmu Nahwu dalam pelajaran bahasa Arab dengan materi yang mengikuti kurikulum pesantren MBS Pleret Bantul. Peneliti memilih penelitian bahasa Arab dengan sub ilmu Nahwu untuk melihat kemampuan peserta didik dalam penggunaan bahasa Arab secara langsung. Dengan mempraktikkan kalimat-kalimat bahasa Arab yang tersusun secara benar, maka akan tercapai tujuan pembelajaran bahasa Arab yang diinginkan oleh sekolah yang bersangkutan.

Sekolah memiliki kebijakan dalam menentukan mata pelajaran yang bersifat muatan lokal seperti pelajaran Imla', Qiro'ah, Nahwu, Sharaf, dan lain-lainnya. Pada saat penelitian dilakukan, semua pelajaran yang terkait dengan bahasa Arab tersebut dipadukan sehingga dapat mencapai empat kemahiran berbahasa Arab, yaitu menyimak (istimâ), berbicara (kalâm), membaca (qiro'ah), dan menulis (kitâbah). Untuk dapat memadukan semua materi dan bahan ajar yang ada di pelajaran bahasa 
Arab, peneliti tentunya membutuhkan media yang menunjang dan memotivasi siswa agar tidak jenuh dalam memahami semua materi dan dapat merespon pelajaran bahasa Arab dengan baik.

\section{HASIL PENELITIAN DAN ANALISIS}

Hasil penelitian yang telah dilakukan di sekolah Muhammadiyah Boarding School (MBS) Pleret Bantul dapat ditunjukkan sebagai berikut:

\section{Tabel 1. Jadwal Pretest}

\begin{tabular}{cccc} 
No. & Hari/Tanggal & Kelas & Waktu \\
\hline 1 & Senin, 21 April 2016 & Putra & $1 \times 40(08.00-08.40)$ \\
\hline 2 & Senin, 21 April 2016 & Putri & $1 \times 40(09.00-09.40)$
\end{tabular}

Pretest dilakukan di kelas putra dan putri secara terpisah karena menyesuaikan sistem yang berlaku dipesantren tersebut, yaitu kelas putra dan putri dipisah. Estimasi waktu pelaksanaannya pada masing-masing kelas adalah 40 menit atau 1 (satu) jam pelajaran.

Tabel 1. Nilai Pretest Kelas Putra

\begin{tabular}{clc} 
No & \multicolumn{1}{c}{ Nama Siswa } & Pretest \\
\hline 1 & Akmal Pamungkas & 37 \\
\hline 2 & Ardan Hanif & 37 \\
\hline 3 & Kandara Syabana Hikmatus Sholih & 95 \\
\hline 4 & Davi Ramadhan Wardana & 68 \\
\hline 5 & Fauzi Attarobi & 28 \\
\hline 6 & Fikhi Taufiqurrahman & 71 \\
\hline 7 & Hafidz Nurul Hayah & 49 \\
\hline 8 & Hanif Hasan Bramantyo & 47 \\
\hline 9 & Muhammad Alfin Azizi & 53 \\
\hline 10 & Muhammad Ridho Riswara & 18 \\
\hline 11 & Muhammad Fadhil Riyanto & 50 \\
\hline 12 & Muhammad Iqbal Alim Syah & 44
\end{tabular}


Siswa putra yang terdaftar dalam pretest sebenarnya berjumlah 14 , namun ada 2 (dua) siswa yang tidak hadir.

Tabel 2. Nilai Pretest Kelas Putri

\begin{tabular}{clc} 
No & \multicolumn{1}{|c}{ Nama Siswa } & Pretest \\
\hline 1 & Aisyah Yuti Pramono & 54 \\
\hline 2 & Alya Fita Diyanti Jinan & 53 \\
\hline 3 & Anggita Safira & 53 \\
\hline 4 & Dinata Wimala & 53 \\
\hline 5 & Difa Difyana & 45 \\
\hline 6 & Ika Malinda Krisnawati & 53 \\
\hline 7 & Sholihah & 40 \\
\hline 8 & Fauziya Lathifah & 38 \\
\hline 9 & Harumi Kahya & 48 \\
\hline 10 & Ita Qiyamul Laili & 48 \\
\hline 11 & Nur Adliya & 40 \\
\hline 12 & Rahmalia Ardia Putri & 76 \\
\hline 13 & Syauqi Hasmayanti Putri & 66 \\
\hline 14 & Tazkiya Saputri & 76 \\
\hline 15 & Fiya Salsabila & 57 \\
\hline 16 & Yauqiq Salimah & 43 \\
\hline 17 & Yustia Putri & 57
\end{tabular}

Siswa putri yang terdaftar dan mengikuti pretest berjumlah 17 siswa.

Dari kedua tabel di atas, kita dapat melihat beberapa nilai yang tidak begitu tinggi sehingga dapat dilakukan proses pembelajaran bahasa Arab dengan media kartu. Kemudian, peneliti menjadikan kelas putra sebagai kelas ekperimen yang mendukung daya serap pemahaman bahasa Arab dengan media kartu.

Tabel 3. Hasil Pretest dan Posttest Kelas Putra

\begin{tabular}{|c|c|c|c|c|}
\hline No & Nama Siswa & Pretest & Posttest & Peningkatan \\
\hline 1 & Akmal Pamungkas & 37 & 55 & 18 \\
\hline 2 & Ardan Hanif & 37 & 58 & 21 \\
\hline 3 & $\begin{array}{l}\text { Kandara Syabana } \\
\text { Hikmatus Sholih }\end{array}$ & 95 & 100 & 5 \\
\hline 4 & $\begin{array}{l}\text { Davi Ramadhan } \\
\text { Wardana }\end{array}$ & 68 & 72 & 4 \\
\hline 5 & Fauzi Attarobi & 28 & 41 & 14 \\
\hline 6 & Fikhi Taufiqurrahman & 71 & 76 & 5 \\
\hline 7 & Hafidz Nurul Hayah & 49 & 49 & 0 \\
\hline 8 & $\begin{array}{l}\text { Hanif Hasan } \\
\text { Bramantyo }\end{array}$ & 47 & 61 & 14 \\
\hline & $\begin{array}{l}\text { Muhammad Alfin } \\
\text { Azizi }\end{array}$ & 53 & 66 & 13 \\
\hline
\end{tabular}




\begin{tabular}{clccc}
10 & $\begin{array}{l}\text { Muhammad Ridho } \\
\text { Riswara }\end{array}$ & 18 & 36 & 18 \\
\hline 11 & $\begin{array}{l}\text { Muhammad Fadhil } \\
\text { Riyanto }\end{array}$ & 50 & 59 & 9 \\
\hline 12 & $\begin{array}{l}\text { Muhammad Iqbal } \\
\text { Alim Syah }\end{array}$ & 44 & 86 & 42
\end{tabular}

Tabel di atas menggambarkan bahwa ada perubahan nilai dari siswa pada posttest setelah eksperimen penggunaan media kartu dilakukan. Ini menunjukkan bahwa jika pembelajaran dengan media kartu dapat diserap dengan baik oleh siswa, maka akan dapat mengembangkan daya ingat siswa dalam proses pembelajaran karena bersifat pengulangan terus menerus dalam permainan kartu. Dengan membagi kelompok bermain, proses pembelajaran akan terus meningkatkan komunikasi yang aktif di antara para siswa dan juga guru. Diskusi materi juga menjadi menarik karena sesuai dengan pertanyaan yang ada pada kartu. Meskipun tidak banyak perubahan pada angka, penelitian ini menunjukkan bahwa dengan menggunakan media kartu dalam proses pembelajaran akan menjadi sebuah solusi dalam meningkatkan daya serap belajar siswa.

Tabel 4. Hasil Pretest dan Posttest Kelas Putri

\begin{tabular}{clccc} 
No & Nama Siswa & Pretest & Posttest & Peningkatan \\
\hline 1 & Aisyah Yuti Pramono & 54 & 58 & 4 \\
\hline 2 & Alya Fita Diyanti Jinan & 53 & 53 & 0 \\
\hline 3 & Anggita Safira & 53 & 54 & 1 \\
\hline 4 & Dinata Wimala & 53 & 52 & 3 \\
\hline 5 & Difa Difyana & 45 & 61 & 16 \\
\hline 6 & Ika Malinda Krisnawati & 53 & 56 & 3 \\
\hline 7 & Sholihah & .40 & 53 & 13 \\
\hline 8 & Fauziya Lathifah & 38 & 42 & 4 \\
\hline 9 & Harumi Kahya & 48 & 52 & 4 \\
\hline 10 & Ita Qiyamul Laili & 48 & 52 & 4 \\
\hline 11 & Nur Adliya & 40 & 52 & 12 \\
\hline 12 & Rahmalia Ardia Putri & 76 & 76 & 0 \\
\hline 13 & Syauqi Hasmayanti Putri & 66 & 66 & 0 \\
\hline 14 & Tazkiya Saputri & 76 & 76 & 0 \\
\hline 15 & Fiya Salsabila & 57 & 57 & 0 \\
\hline 16 & Yauqiq Salimah & 43 & 47 & 4 \\
\hline 17 & Yustia Putri & 57 & 61 & 4
\end{tabular}


Hasil yang ditampilkan pada tabel di atas adalah data nilai kelas putri yang tidak di-treatment dengan penggunaan media kartu dan dilakukan pembelajaran seperti biasanya. Dalam tabel tersebut, kita dapat melihat bahwa nilai pretest siswa kelas putri mengungguli nilai pretest siswa kelas putra sebelum dilakukan treatment dengan media kartu. Kemudian, keadaannya berubah pada saat posttest, yaitu nilai kelas putra mengalami perbaikan dan peningkatan. Di sisi lain, nilai kelas putri tidak mengalami perubahan yang signifikan, bahkan ada beberapa siswa putri yang justru mengalami penurunan nilai.

Mari kita lihat tabel di bawah ini dengan deskripsi statistik:

Tabel 5. Deskripsi Statistik

\section{Statistics}

\begin{tabular}{lcccc}
\hline & EKS_PRE & EKS_POST & KON_PRE & KON_POST \\
\hline$N$ & 12 & 12 & 17 & 17 \\
\hline Mean & 49.67 & 63.25 & 52.94 & 56.53 \\
\hline Minimum & 18 & 36 & 38 & 42 \\
\hline Maximum & 95 & 100 & 76 & 76
\end{tabular}

Mean adalah nilai tengah dari kedua kelas yang telah diteliti

Min adalah nilai terendah kedua kelas yang telah diteliti

Max adalah nilai tertinggi kedua kelas yang telah diteliti

Tabel tersebut menunjukkan bahwa Nilai Tengah kelas putra pada awal atau pretest hanya 49.67 dan untuk kelas putri 52.94. Setelah proses pembelajaran dilakukan dengan menggunakan media, kita menemukan bahwa hasil Nilai Tengah kelas eksperimen (kelas putra) mencapai 63.25 dan kelas kontrol (kelas putri) hanya mencapai 56.53. Ini menandakan bahwa proses pembelajaran menggunakan media kartu dapat meningkatkan daya serap belajar siswa dan memberikan pengaruh yang besar sehingga metode pembelajaran dengan media ini dapat dijadikan solusi dalam penyampaian materi ajar secara maksimal.

\section{KESIMPULAN DAN SARAN}

Hasil penelitian eksperimen yang telah dilakukan di sekolah Muhammadiyah Boarding Schoool (MBS) Pleret Bantul menunjukkan perubahan pola pembelajaran siswa dalam memahami materi pada Kegiatan Belajar Mengajar (KBM) karena siswa mendapatkan banyak kesempatan berdiskusi untuk menyampaikan jawaban yang tepat berkaitan dengan materi ajar sesuai jenjangnya. Pola pembelajaran di kelas mengalami perubahan yaitu dari siswa hanya mendengarkan dan melatih diri untuk memahami penjelasan seorang guru menjadi siswa dituntut dengan gaya memahami masing-masing dilakukan dengan pembelajaran menggunakan media kartu.

Media kartu merupakan jembatan transfer pengetahuan yang dapat mengasah kemampuan siswa dalam berdialog dan mempertahankan argumennya, serta 
mendapatkan pengetahuan yang lebih atau dapat mengoreksi setiap pemahaman yang keliru. Tentu saja pembelajaran dengan menggunakan media kartu ini membutuhkan suasana yang menyenangkan dalam belajar sehingga peneliti menggabungkan antara pembelajaran, media, dan permainan dengan media kartu tersebut. Kegiatan pembelajaran dengan banyak permainan tentunya lebih disukai siswa karena tidak membosankan. Hanya saja, guru dan sekolah harus menyediakan waktu yang panjang dan cukup untuk terciptanya pembelajaran yang kondusif.

Peneliti menyarankan bahwa dalam menggunakan media kartu guru harus menguasai betul materi yang akan disampaikan sebelum melakukan proses pembelajaran. Siswa juga harus diberikan stimulus atau gambaran materi yang akan dibahas serta diberikan arahan saat permainan berlangsung. Peran guru dalam penelitian ini adalah menilai keaktifan setiap siswa untuk mengetahui kemampuan yang selama ini tidak pernah terlihat. Kegiatan pembelajaran ini seluruhnya akan berpusat kepada siswa atau yang dikenal dengan Student Centered Learning (SCL). Selanjutnya, peneliti juga menyarankan kepada peneliti-peneliti selanjutnya agar memahami kondisi sekolah dan siswa supaya KBM tersebut membutuhkan waktu yang efisien dalam penyampaian materi.

\section{REFERENSI}

Anitah, Sri. 2012. Media Pembelajaran. Surakarta: Yuma Pustaka.

Arikunto, Suharsimi. 2006. Penelitian Tindakan Kelas. Jakarta: Bumi Aksara.

Asrori, Imam. Strategi Belajar Bahasa Arab Teori \& Praktek. Cet. I. Malang: Misykat, 2012.

Daud, Muhammad Muhammad. Al-'Arabiyyah wa 'Ilm al-Lughah al-Haditsah. Cairo: Dâr Gharî́b.

Khalilullah, M. 2008. Media Pembelajaran Bahasa Arab. Yogyakarta: Aswaja.

Margono. 2004. Metodologi Penelitian Pendidikan. Jakarta: PT Asdi Mahastya.

Mujib, Fathul. 2012. Super Power In Educating. Yogyakarta: Diva Press.

Satori, Djam'an dan Komarudin, Aan. 2013. Metodologi Penelitian Kualitatif. Bandung: Alfabeta.

Sudijono, Anas. 2013. Evaluasi Pendidikan. Jakarta: Rajawali Pers.

Sugiyono. 2013. Metode Penelitian (Pendekatan Kuantitatif, Kualitatif, dan R\&D). Bandung: Alfabeta.

Sukardi, M. 2012. Evaluasi Pendidikan Prinsip \& Operasionalnya. Jakarta: Bumi Aksara. Sukmadinata, Nana Syaodih. 2011. Metode Penelitian Pendidikan. Bandung: PT Remaja Rosdakarya.

Sunarti dan Rahmawati, Selly. 2014. Penilaian dalam Kurikulum 2013. Yogyakarta: Andi. 